\title{
Global Prediction of Continuous Hydrocarbon Accumulations in Self-Sourced Reservoirs
}

\section{By Jennifer D. Eoff}

\section{Abstract}

Shale resource plays occur in predictable tectonic settings within similar orders of magnitude of eustatic events. A conceptual model for predicting the presence of resource-quality shales is essential for evaluating components of continuous petroleum systems

Basin geometry often distinguishes self-sourced resource plays from conventional plays. Intracratonic or intrashelf foreland basins at active margins are the predominant depositional settings among those explored for the development of selfin rifted passive margin settings (or other crote supercontinents, and the latter often resulted during or subsequent to the breakup of landmasses. Spreading rates, climate, and eustasy are influenced by these global tectonic events, such that deposition of self-sourced reservoirs occurred during periods characterized by rapid plate reconfiguration, predominantly greenhouse climate conditions, and in areas adjacent to extensive carbonate sedimentation. Combined tectonic histories, eustatic curves, and paleogeographic reconstructions may be useful in global predictions of organic-rich shale accumulations suitable for continuous resource development.

Accumulation of marine organic material is attributed to upwellings that enhance productivity and oxygen-minimum bottom waters that prevent destruction of organic matter. The acurn wation of potential self-soutced resoutees can be attributed to slow sedimenting the and other cratonic highs occurred. In contrast, deposition of this resource type on rifted passive margins was likely the result of thick sections of clastic material, following thermal relaxation after plate collision or rift phases, advances kerogen maturation.

With few exceptions, North American self-sourced reservoirs appear to be associated with calcitic seas and predominantly greenhouse or transitional ("warm" to "cool") global climatic conditions. Significant changes to the global carbon budget may also be a contributing factor in the stratigraphic distribution of continuous resource plays, requiring additional evaluation.

\section{Introduction}

Continuous liquids-rich and gas accumulations in the Marcellus, Barnett, and Eagle Ford Shales, and the Bakken and Haynesville-Bossier Formations, satisfy some of the increasing demands for energy, and the need for global prospects is growing.

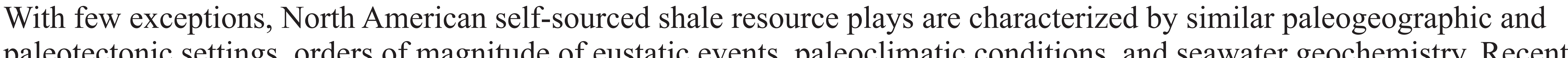
paleotectonic settings, orders of magnitude of eustatic events, paleoclimatic conditions, and seawater geochemistry. Recently, mechanical properties of successful self-sourced shale plays, such as the Mississippian Barnett Shale in Texas.

Many mechanisms may be responsible for the deposition and preservation of uncommonly thick accumulations of marine organic matter, such that differentiation among various causes and feedback mechanisms is challenging. The formation of selfsourced shale reservoirs appears to be limited to discrete periods in geological history, indicating that atypical combinations of geological and paleonvironmental processes were responsible. Data from several disciplines within the geosciences were compiled against a common geologic timescale to address questions of scientific and economic interest.

Not all mature hydrocarbon source rocks are effective self-sourced reservoirs. The stratigraphic distribution of continuous hydrocarbon accumulations in self-sourced shales requires a conceptual model to support empirical studies and global exploration of these important resources.

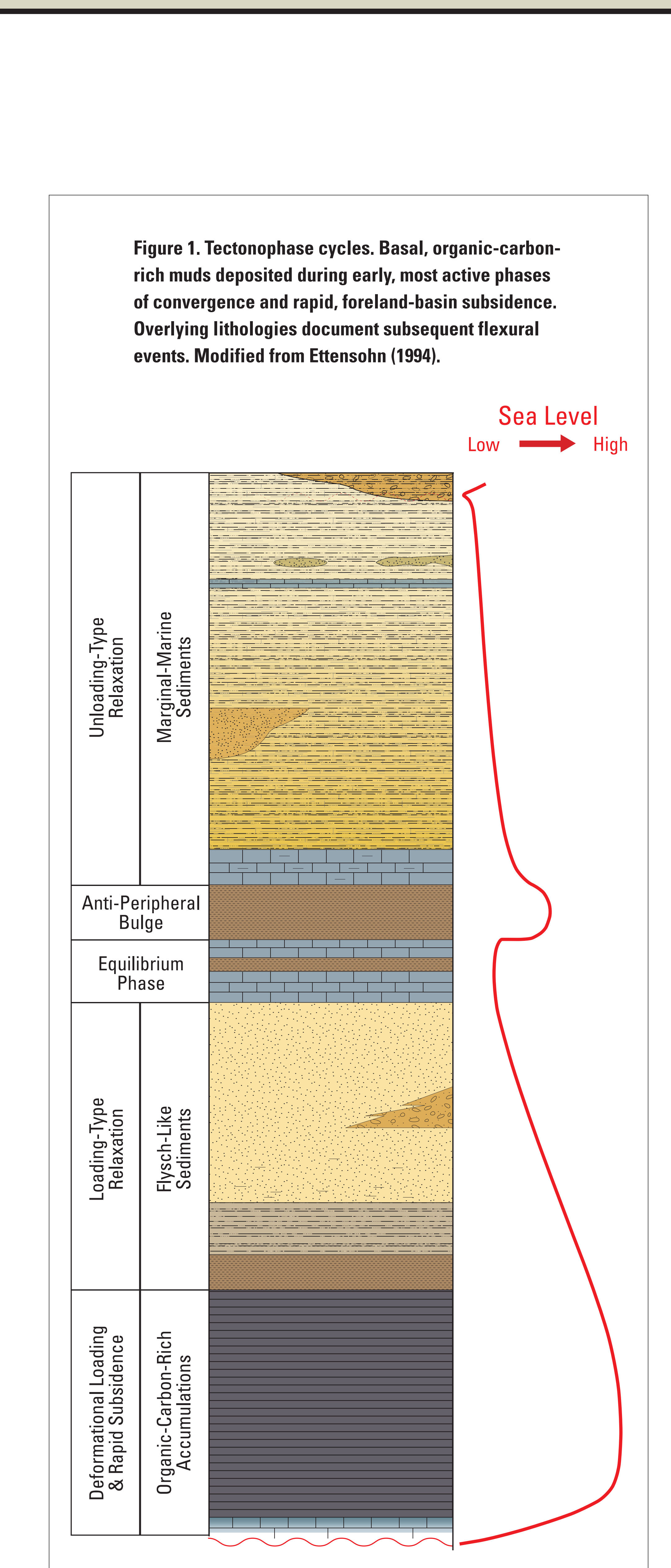

Tectonics and Paleogeography

Tectonics - Tectonics was the initial driver behind a complex, atypical combination of processes that promoted theck accint Pigott, 1981, Sandigen, 1983, Waples, 1983) (fig. 1). A number of feedback mechanism associated with widespread volcanis, dung rapid tectonic movements increased in in global tenperatures, and elevated sea-sultace temperates, secondary effects included Foreland and intra Paleozoic, whereas semi-restricted basins along rifted passive margins dominated the Mesozoic of the Gulf Coast (fig. 2). The latter were associated with reactivation of longlived basement features or salt tectonics. (Eoff, 2012, written commun., for a complete tectonic model)
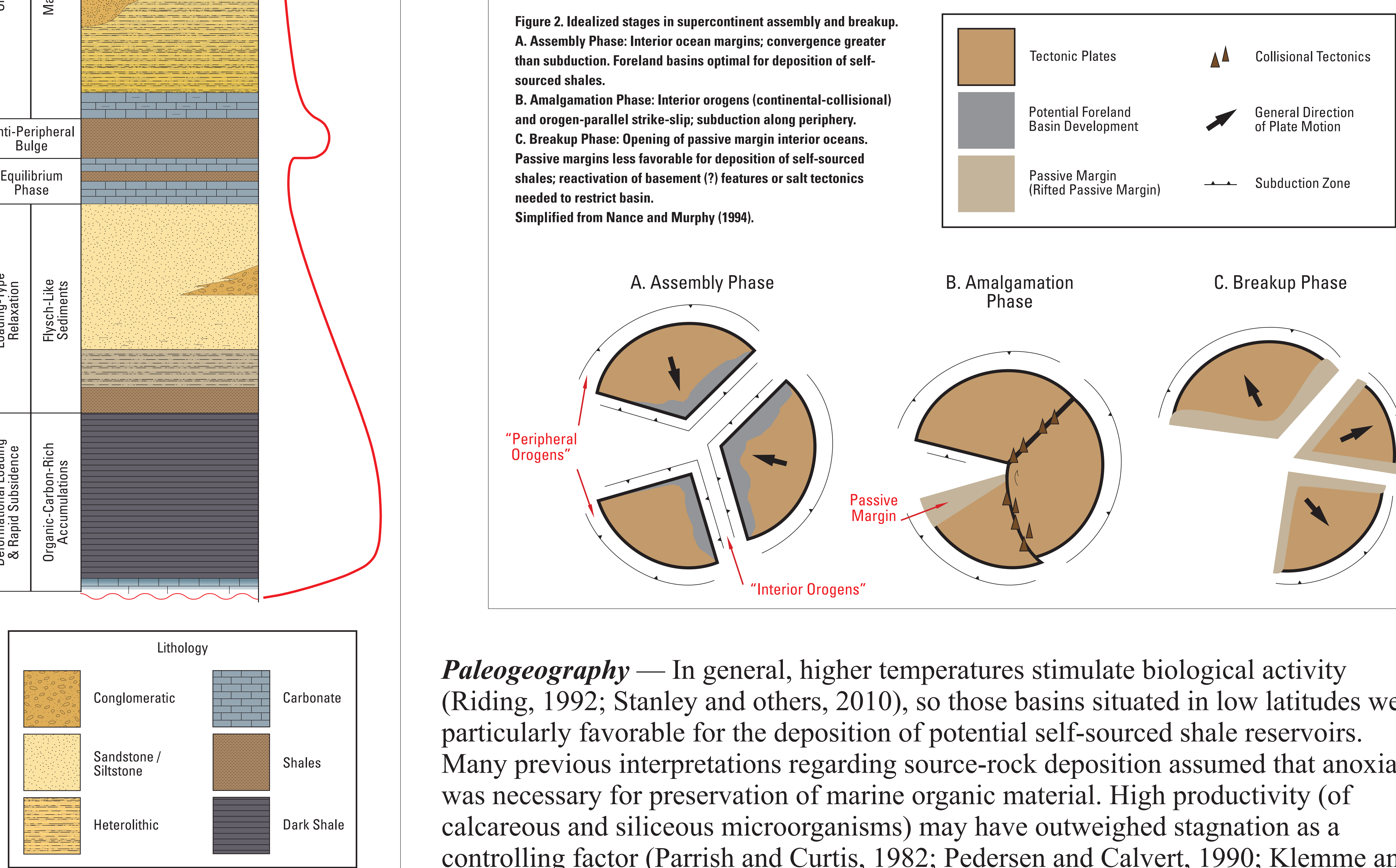

Paleogeography - In general, higher temperatures stimulate biological activity (Riding 1992. Stanley and others, 2010), so those basins situted in low latitudes were particularly favorable for the deposition of potential self-sourced shale reservoirs. Many previous interpretations regarding source-rock deposition assumed that anoxia was necessary for preservation of marine organic material. High productivity (of calcareous and siliceous microorganisms) may have outweighed stagnation as a controlling factor (Parrish and Curtis, 1982, Pedersen and Calvert, 1990; Klemme and Ulmishek, 1991), thus, exploration for new self-sourced conthuous hydrocarbo accumulations should not be restricted to stratigraphic sections of inferred (See figure 4 for paleogeographic example). 